\title{
A Micro-Computed Tomography (micro-CT) Analysis of Postmenopausal Osteoporotic Rat Models Supplemented with Ficus carica
}

\author{
Adlina Mohammad ${ }^{1}$, Norfarah Izzaty Razaly ${ }^{1}$, Mohd Dzulkhairi Mohd Rani ${ }^{1}$, Muhammad Shamsir Mohd Aris ${ }^{1}$, \\ Sulaiman Md Dom ${ }^{2}$, Nadia Mohd Effendy ${ }^{1 *}$ \\ ${ }^{1}$ Faculty of Medicine and Health Sciences Universiti Sains Islam Malaysia, Persiaran MPAJ, Pandan Indah, 55100, Kuala Lumpur, Malaysia. \\ ${ }^{2}$ School of Medical Imaging, Faculty of Health Sciences, Universiti Teknologi MARA Cawangan Selangor, 42300 Puncak Alam, Malaysia.
}

\section{ARTICLE INFO \\ Article history: \\ Received on: $12 / 02 / 2018$ \\ Accepted on: 08/05/2018 \\ Available online: 29/06/2018}

\section{Key words:}

Postmenopausal

osteoporosis; ovariectomy;

Ficus carica; estrogen; bone microarchitecture;

micro-CT.

\begin{abstract}
Estrogen replacement therapy (ERT) is known to be effective as an anti-osteoporotic treatment for postmenopausal women but exerted many adverse effects. Ficus carica (FC) or fig is a fruit rich in antioxidants and anti-inflammatory sources that are believed to contribute to its potential as ERT alternative. This study aimed to evaluate the effects of FC supplementation on the trabecular microarchitecture of postmenopausal osteoporotic rat models. Fifty-six adult female Sprague-Dawley rats were randomly divided into groups of Sham-operated (Sham), ovariectomized control (OVX), ovariectomized with $64.5 \mu \mathrm{g} / \mathrm{kg}$ estrogen Premarin (ERT), ovariectomized with $50 \mathrm{mg} / \mathrm{kg}$ aqueous extract of FC (FC50), ovariectomized with $100 \mathrm{mg} / \mathrm{kg}$ aqueous extract of FC (FC100), ovariectomized with $50 \mathrm{mg} / \mathrm{kg}$ raw extract of FC (RAW50) and ovariectomized with $100 \mathrm{mg} / \mathrm{kg}$ raw extract of FC (RAW100). The treatments were given daily via oral gavage for eight weeks. After the treatment, rats were euthanized and femora were dissected out for micro-computed tomography (micro-CT) analysis. Trabecular structure of OVX femur showed significant osteoporotic deterioration in bone volume, trabecular separation, structural model index and connectivity density. ERT significantly reversed the osteoporotic-induced bone changes comparable to Sham level. RAW50 showed the best FC treatment in preserving bone microarchitecture. In conclusion, raw extraction of FC has high potential as an alternative against osteoporosis due to its high mineral contents and bioactive compounds.
\end{abstract}

\section{INTRODUCTION}

Bone mass is regulated by the balance between osteoclast and osteoblast activities. Osteoporosis is a state where bone resorption activity overwhelms the bone formation activity. In women, estrogen deficiency after menopause causes acceleration of bone resorption activity and this lead to osteoporosis which is a common skeletal disorder among the women (Manolagas, 2010; Miyauchi et al., 2013). Therefore, osteoporosis is more prevalent among postmenopausal women than men as estrogen plays a

\footnotetext{
"Corresponding Author

Nadia Mohd Effendy, Faculty of Medicine and Health Sciences, Universiti Sains Islam Malaysia, Menara B, Persiaran MPAJ, Jalan Pandan Utama, Pandan Indah, 55100 Kuala Lumpur, Malaysia. E-mail:nadia@usim.edu.my
}

crucial role in bone regulation (Faienza et al., 2013; Tian et al., 2017). It was recorded in Europe in 2010, that $21 \%$ of women aged above 50 years old are classified as osteoporosis which was three times greater than men that recorded only $6 \%$ (Hernlund et al., 2013).

Since estrogen plays a crucial role in bone regulation, hormone replacement therapy is one of the common conventional treatments used against postmenopausal osteoporosis. Even though it is proposed as an effective treatment for reducing bone osteoporotic changes in postmenopausal osteoporotic women, its long-term use may be accompanied by adverse effects such as breast cancer, stroke, thromboembolism and ovarian cancer (Bernabei et al., 2014; Sood et al., 2014). Other treatments used against osteoporosis include selective estrogen receptor modulators (SERMs) such as raloxifene, and biphosphonates such 
as alendronate and risedronate (Goldhahn et al., 2010; Huang et al., 2010; Inderjeeth et al., 2012). Both SERMs and bisphosphonates are anti-resorptive agents that inhibit the acceleration of bone resorption activity, thereby increasing bone mineral density and preserving the bone structure (Das and Crockett, 2013). However, most of these drugs showed detrimental side effects such as esophageal cancer, hypocalcemia, gastrointestinal intolerance, atrial fibrillation, venous thromboembolism, and stroke (Abrahamsen, 2010; Rizzoli et al., 2011; Mcclung et al., 2013). Hence, the use of natural products with anticipating fewer side effects might provide an alternative approach in managing postmenopausal osteoporosis.
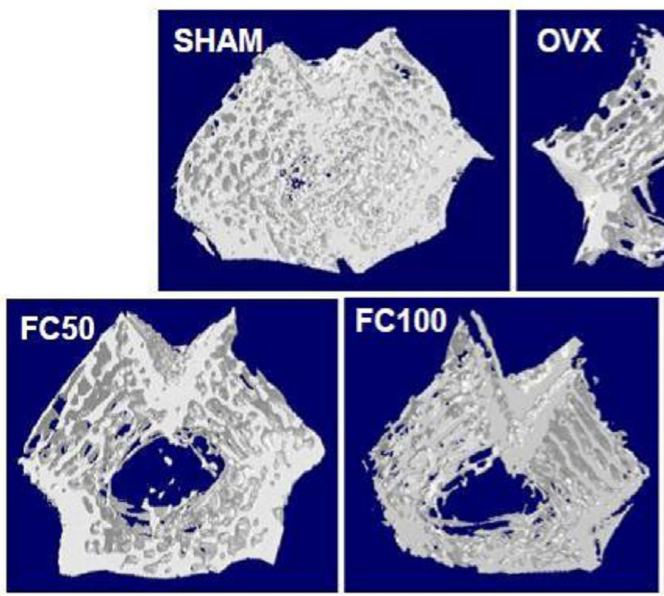

Fig. 1: The 3D image of bone microarchitecture of each group.
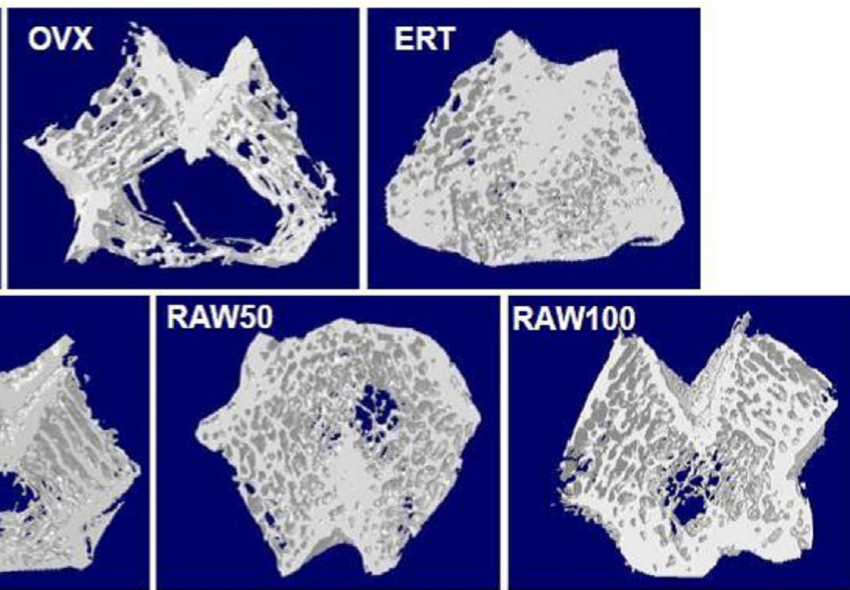

Table 1: The minerals and phytochemicals contents of fresh fruit $F$. carica.

\begin{tabular}{rc}
\hline \multicolumn{1}{c}{ Mineral contents } & \\
\hline Calcium & $22.44 \mathrm{mg} / 100 \mathrm{~g}$ \\
Magnesium & $9.42 \mathrm{mg} / 100 \mathrm{~g}$ \\
Zinc & $0.53 \mathrm{mg} / 100 \mathrm{~g}$ \\
Phytochemical contents & - \\
Alkaloids & + \\
Saponins & + \\
Flavonoids & + \\
Tanins & + \\
Steroids & - \\
Triterpenes & \\
\hline
\end{tabular}

+ Indicate the presence of content, - indicate the absence of content.

Some of the new natural alternatives that were proposed to have anti-osteoporotic properties with minimal side effects are extracts of Labisia pumila, virgin coconut oil, mulberry and blackcurrant (Abujazia et al., 2012; Zheng et al., 2016; Nadia et al., 2014; Jao et al., 2016). These plants contain antioxidative bioactive compounds such as polyphenols, flavonoids, anthocyanins, ferulic acid and p-coumaric acid, which were reported to have the capability in improving bone strength as well as preventing or reducing the bone loss of ovariectomized rat models (Levis and Lagari, 2012; Romero and Rivas, 2014). They inhibited the bone resorption activity by scavenging the superoxide radical and suppressed the lipid peroxidation (Abujazia et al., 2012).

Ficus carica or common fig is another fruit which is believed to contain a high level of antioxidant properties after berries (Çalişkan and Aytekin Polat, 2011; Mawa et al., 2013; Harzallah et al., 2016). F. carica is also known to contain an abundance of minerals such as calcium, magnesium, and strontium which are important for bone health (Joseph and Raj, 2011; Pareira et al., 2017). Due to its high antioxidant and nutritional contents, $F$. carica has potentials as an alternative treatment in preserving and preventing postmenopausal osteoporosis. This experimental study is aimed to evaluate the effects of $F$. carica on the bone microarchitecture in osteoporotic rat models. Bone microarchitecture evaluations were accessed using micro-computed tomography (micro-CT) replacing the conventional methodology, histomorphometry which is limited to two-dimensional information, destructive techniques, and timeconsuming (Kochi et al., 2010). Micro-CT is known to be effective in determining the efficiency of pharmacological interventions on bone using three-dimensional structures which give the insight of bone microarchitecture. The microarchitectural structure provided is used as an indicator of bone mass, strength, density which aids in diagnosis the risk of osteoporosis (Kim and Henkin, 2013; Fonseca et al., 2014).

\section{MATERIAL AND METHODS}

\section{Animal and treatment}

This study was performed according to the experimental protocol approved by Universiti Sains Islam Malaysia Animal Ethics Committee (USIM/AEC/AUP/2016(4)). A total of 56 female Sprague-Dawley rats aged five to six months weighing between $200 \mathrm{~g}$ to $250 \mathrm{~g}$ were used in this study. The rats were housed in a ventilated cage at a temperature of $29^{\circ} \mathrm{C} \pm 3^{\circ} \mathrm{C}$ under natural day/night cycle. They were supplied with normal food pellets (Gold Coin, Malaysia) and tap water ad libitum. They were acclimatized to the new environment for a week before the study was started. The rats were randomly assigned into groups of Sham- 
operated (Sham), ovariectomized control (OVX), ovariectomized with supplementation of $64.5 \mu \mathrm{g} / \mathrm{kg}$ of estrogen Premarin (ERT), ovariectomized with supplementation of $50 \mathrm{mg} / \mathrm{kg} F$. carica aqueous extract (FC50), ovariectomized with supplementation of $100 \mathrm{mg} / \mathrm{kg} F$. carica aqueous extract (FC100), ovariectomized with supplementation of $50 \mathrm{mg} / \mathrm{kg} F$. carica raw extract (RAW50) and ovariectomized with supplementation of $100 \mathrm{mg} / \mathrm{kg}$ F. carica raw extract (RAW100). Rats were ovariectomized to induce an osteoporotic state. The treatments started two weeks following the ovariectomy to ensure healing of the rats as well as successful osteoporosis induction. The treatments were given daily, for eight weeks via oral gavages.

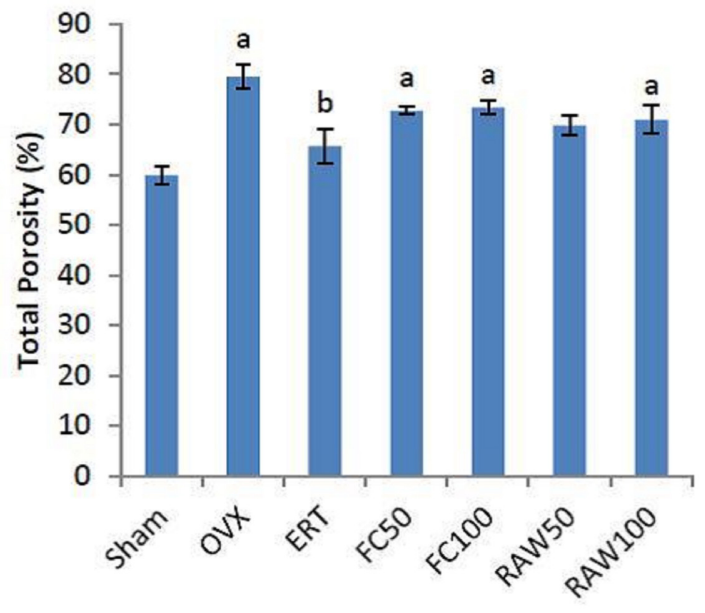

Fig. 2: Mean percentage of total porosity of all groups. Data presented as mean $\pm \operatorname{SEM}(p<0.05)$ with standard error bars of the average values. 'a' indicates there was significant difference with Sham group and 'b' indicated there was significant difference with OVX group.

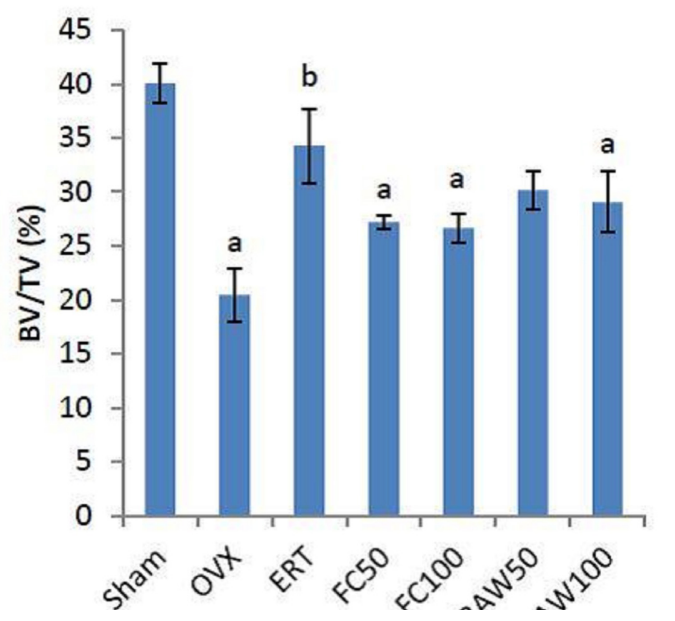

Fig. 3: Mean bone volume fraction percentage of all groups. Data presented as mean \pm SEM $(p<0.05)$ with standard error bars of the average values. 'a' indicates there was significant difference with Sham group and ' $b$ ' indicated there was significant difference with OVX group.

\section{Ficus carica (FC) and Estrogen (ERT) preparation}

Fresh $F$. carica (FC) were obtained from fig Fertigation (Sungai Ramal Dalam Kajang, Selangor). The fresh Ficus carica fruits were sent to Malaysian Agricultural Research and
Development Institute (MARDI) and Forest Research Institute Malaysia (FRIM) for the mineral content and phytochemical test (Table 1). The F. carica raw extraction was prepared by using 1:1 ratio of raw figs and deionized water $(100 \mathrm{mg}$ : $100 \mathrm{ml})$ for $100 \mathrm{mg}$ / $\mathrm{kg}$ solution and 1:2 ratio of raw figs and deionized water $(100 \mathrm{mg}$ : $200 \mathrm{ml}$ ) for $50 \mathrm{mg} / \mathrm{kg}$ solution. Aqueous extraction of $F$. carica was performed by Phytes Biotek Sdn Bhd (Shah Alam, Malaysia). The sample was extracted using an extractor with ratio $1 \mathrm{~kg}$ (raw FC): $10 \mathrm{~L}$ (reversed osmosis water) at $95^{\circ} \mathrm{C}$ for 3 hours. Then, the extracted sample was freeze-dried and evaporated at $70^{\circ} \mathrm{C}-80^{\circ} \mathrm{C}$ in vacuum condition until the minimum volume of concentrate was achieved. The concentrated liquid was further concentrated using rotary evaporator and freeze-dried into powder at a temperature between $-20^{\circ} \mathrm{C}$ to $30^{\circ} \mathrm{C}$ for three days. The extracted powder was dissolved in deionized water for $50 \mathrm{mg} / \mathrm{kg}$ and $100 \mathrm{mg} / \mathrm{kg}$ dosage of rat weight. Estrogen Premarin (Wyeth-Ayerst, Canada) tablets containing conjugated estrogen were crushed, dissolved in deionized water and were given via oral gavage at the dose of 64.5 $\mu \mathrm{g} / \mathrm{kg}$ rat weight. The treatments were given daily for 8 weeks via oral gavage.

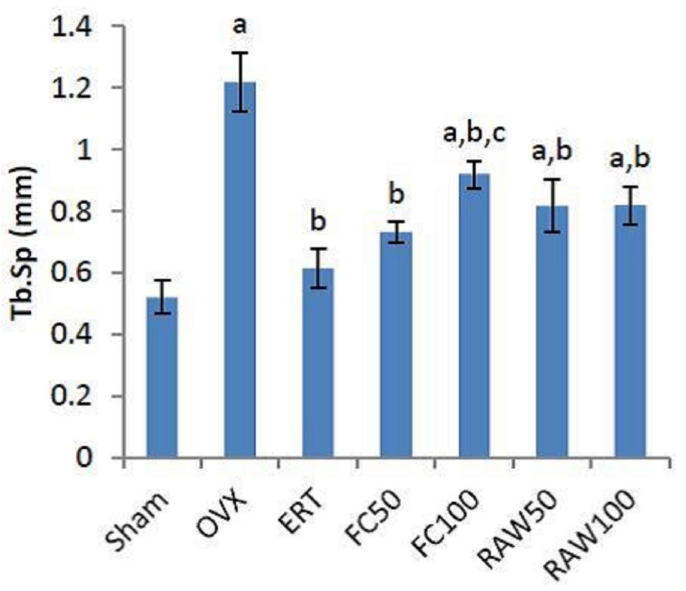

Fig. 4: Trabecular separation values of each group. Data presented as mean \pm SEM $(p<0.05)$ with standard error bars of the average values. ' $a$ ' indicates there was significant difference with Sham group; ' $b$ ' indicated there was significant difference with OVX group and 'c' indicates there was significant difference with ERT group.

\section{Bone sampling}

Rats were put into euthanasia by an overdose of diethyl ether via inhalation. After the rats were sacrificed, the muscles and tissues of the limb were cut to expose the femora. Then, the hip and knee joints were cut to remove the femora. The muscle tissues attached around the femora were cleaned and removed. The clean femora were kept in $10 \%$ formalin solution at room temperature for preservation prior to bone microarchitecture tests.

\section{Bone microarchitecture analysis}

Bone microarchitecture analysis was done using micro-CT scanner (Bruker SkyScan 1176, Belgium) at the Department of Medical Imaging, UiTM Puncak Alam, Selangor. The femur was dried superficially and wrapped with parafilm to maintain normal hydration of bone during the scanning. The femur was put horizontally into a $6.0 \mathrm{~cm}$ polystyrene foam tube 
to hold the sample and mounted on the sample bed in the vertical axis of the scanner. The scanner was set at medium Al $0.5 \mathrm{~mm}$ filter, $18 \mathrm{~m}$ pixel resolution and 0.4 rotation degree. The current, voltage, and exposure were selected depending on the bone where the transmission profile value was read within the range of $27 \%$ $32 \%$. The projected images after scanning were reconstructed using NRecon V1.6.4.0 (SkyScan) software and the datasets of reconstructed images were then analyzed using CT Analyser (CTAn V1.11.10; SkyScan). The region of interest (ROI) was set at $1.347 \mathrm{~mm}$ from the growth plate extended to a further $2.200 \mathrm{~mm}$ with total of 200 slices. This ROI is the trabecular region which is rich in blood supply and has high bone turnover activities. The 3D morphometric parameters were measured which include total porosity, bone volume fraction (BV/TV), bone surface fraction (BS/BV), trabecular thickness (Tb.Th), trabecular number (Tb.N), trabecular separation (Tb.Sp), connectivity density (Conn.Dn), structural model index (SMI) and degree of anisotropy (DA).

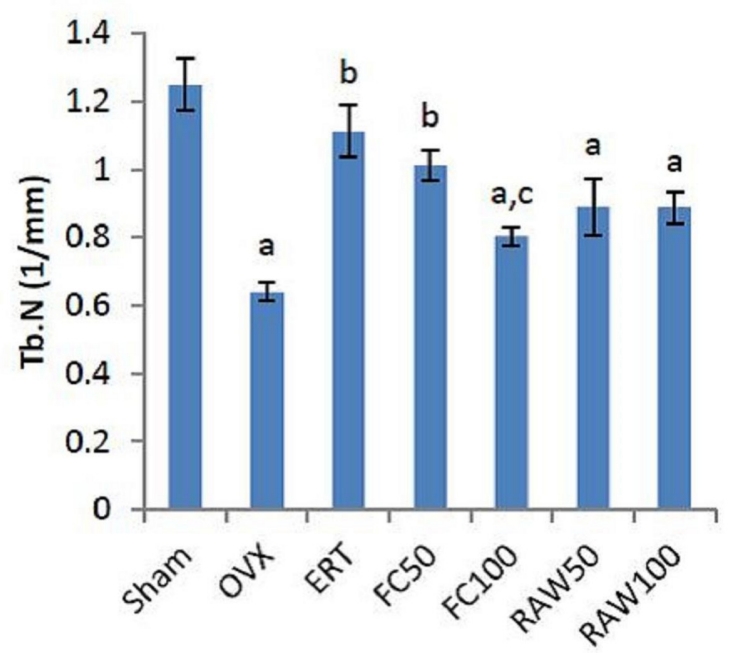

Fig. 5: Mean trabecular numbers of each group. Data presented as mean $\pm \mathrm{SEM}$ $(p<0.05)$ with standard error bars of the average values. ' $a$ ' indicates there was significant difference with Sham group; ' $b$ ' indicates there was significant difference with OVX group and ' $c$ ' indicates there was significant difference with ERT group.

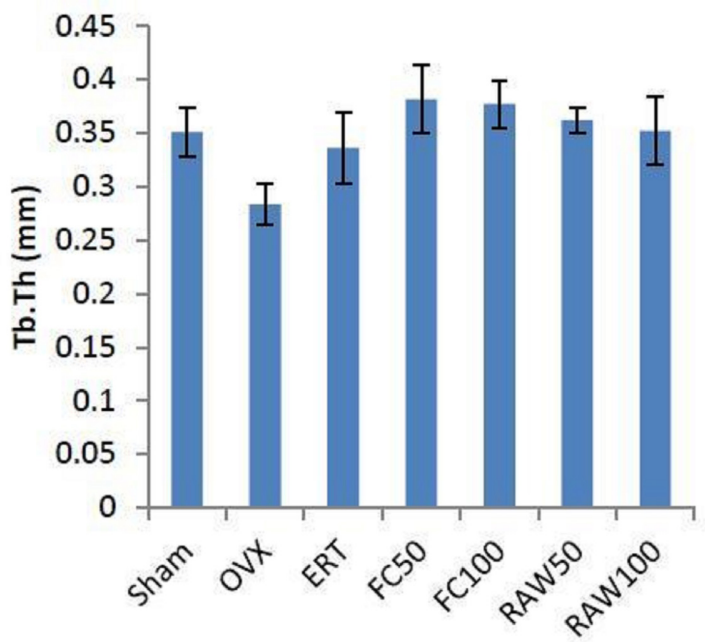

Fig. 6: Mean trabecular thickness values of all groups. Data presented as mean \pm SEM $(p<0.05)$ with standard error bars of the average values.

\section{Statistical analysis}

The data was analyzed using Statistical Package for Social Science software version 24.0 (SPSS 24.0, Chicago, USA). The normally distributed data were tested using analysis of variance (ANOVA) followed by Tukey's HSD test. For not normally distributed data were tested using Kruskal-Wallis and Mann-Whitney tests. All the results were expressed as mean standard error of the mean (SEM).

\section{RESULT AND DISCUSSION}

Osteoporosis is a global health issue due to its longterm outcome which may affect the quality of life of a person as well as country's economic development. It is a systemic skeletal disease characterized by low bone mass and microarchitectural deterioration resulting in bone fragility and susceptibility to fracture (Peck, 1993). Once a fracture occurred, an individual will experience pain, limited physical function, immobility, and social and emotional problem. A study reported that after one year of hip fracture, $25 \%$ of the patients have died, $40 \%$ can walk poorly or wheelchair bound, and $60 \%$ can walk more or less the same as before the fracture (Klein-Nulend et al., 2015).

Higher incidence of osteoporosis among the women is highly associated with the decreased estrogen level when they hit menopause (Khosla et al., 2010; Svejme et al., 2012). Estrogen replacement therapy (ERT) is one of the conventional treatments used by the postmenopausal women in order to preserve bone from deteriorating and to avoid fracture from occurring. However, this therapy is compromised by long-term side effects such as gastrointestinal intolerance, ovarian and breast cancer (Narod, 2011; Ritte et al., 2012; Chung et al., 2016). Hence, previous studies were proposed alternatives from the natural plants with fewer side effects in managing osteoporosis. Ficus carica was proposed in this study as an alternative treatment against osteoporosis due to its mineral content and antioxidant properties (Table 1) which believes to improve bone health as demonstrated by other past studies.

The morphometric change in bone structure is a key indicator for determining osteoporosis status and the risk of fracture to occur. In the present study, the trabecular bone was assessed using micro-CT. Micro-CT is a tool that produces high measurement accuracy of trabecular bone calculation with threedimensional images. Micro-CT provides both metric and nonmetric bone parameters. Metric parameters include bone volume fraction (BV/TV), trabecular thickness (Tb.Th), trabecular number (Tb.N), and trabecular separation (Tb.Sp). Non-metric parameters include connectivity density, structural model index (SMI) and degree of anisotropy (DA) (Nishiyama et al., 2010; Ito, 2011).

Ovariectomy has been proved and used by many studies as estrogen-deficiency osteoporosis model. As expected, OVX group showed a massive loss of trabecular connections (Figure 1) and recorded the most porous bone structure (Figure 2). This is supported by previous studies which also reported on the deterioration of ovariectomized rat's trabecular bone structures (Mohamed et al., 2012; Bouxsein et al., 2010). Estrogen supplementation group (ERT) showed reversing bone osteoporotic changes with denser trabecular microarchitecture as shown by the $3 \mathrm{D}$ images (Figure 1) and significantly better trabecular 
connection with low porosity (Figure 2). Both aqueous and raw extracts of FC treatments were found to have a better 3D image of bone microarchitecture than OVX group. RAW50 showed the best microarchitecture among the treatment groups with fewer bone deteriorations (Figure 1).

$\mathrm{BV} / \mathrm{TV}$ is the fraction of mineralized bone which occupies a given volume of interest (Perilli et al., 2010). It can be used as predictors of bone stiffness, density and mechanical properties (Maquer et al., 2015). OVX group showed significantly lower BV/TV (Figure 3). This finding is supported by the past studies where ovariectomized rats recorded low BV/TV due to bone perforation following estrogen deficiency (Li et al., 2013; Spilmont et al., 2014; Liu et al., 2015). Other metric parameters are $\mathrm{Tb}$.Th which measures the mean thickness of trabeculae, Tb.N measures the average number of trabeculae per unit length and Tb.Sp measures the mean distance between trabeculae (Bouxsein et al., 2010). An osteoporotic bone is porous due to the thinning of $\mathrm{Tb}$. Th caused by bone resorption which then degenerates and leads to the loss of Tb.N. As Tb.N start to decrease, the distance between the bone (Tb.Sp) is increased. As shown by the current study, the ovariectomized control group had significantly lower Tb.N (Figure 5) and higher Tb.Sp values (Figure 4). ERT group improved the deteriorated bone with significantly higher BV/TV and Tb.N, and lower Tb.Sp than OVX group. RAW50 recorded higher BV/TV (Figure 3) and significantly lower Tb.Sp (Figure 4) compared to OVX group which was comparable to ERT and Sham groups. All treatment groups showed significantly lower Tb.Sp (Figure 4) than OVX group and FC50 group showed significantly higher Tb.N than OVX group (Figure 5), but not significantly different with the other treatment groups. This concludes that all FC extracts showed potential in improving the trabecular structure of osteoporotic bone.

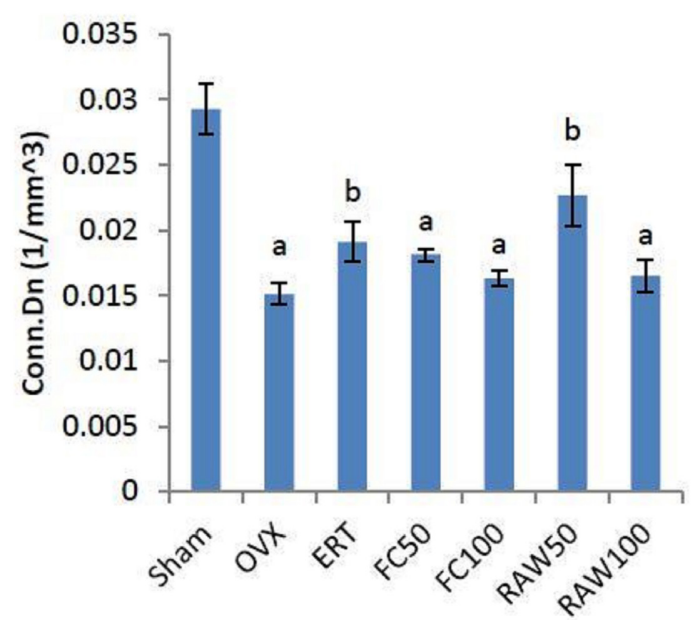

Fig. 7: Connectivity density values of each group. Data presented as mean \pm SEM $(p<0.05)$ with standard error bars of the average values. ' $a$ ' indicates there was significant difference with Sham group and ' $b$ ' indicated there was significant difference with OVX group.

Tb.Th was not significantly different between all the groups even though the treatment groups showed an increment trend higher than OVX group (Figure 6). Studies were done by Francisco et al. (2011) reported that ovariectomy caused a reduction in a total number of $\mathrm{BV} / \mathrm{TV}$ and $\mathrm{Tb} . \mathrm{N}$ and increased
Tb.Sp while Tb.Th did not change significantly. Other findings also showed that increasing of bone connectivity does not significantly increase trabecular thickness. This is supported by studies done by Ahn et al. (2012) and Nadia et al. (2017) which reported no significant difference of $\mathrm{Tb}$. Th value between the intervention groups and negative control group. These similar findings may be due to ovariectomy which caused a gradual loss in bone structure where the trabecular structures changed radically from plate-like to rod-like hence, making the $\mathrm{Tb}$. Th measure not significant (Parkinson and Fazzalari, 2013).

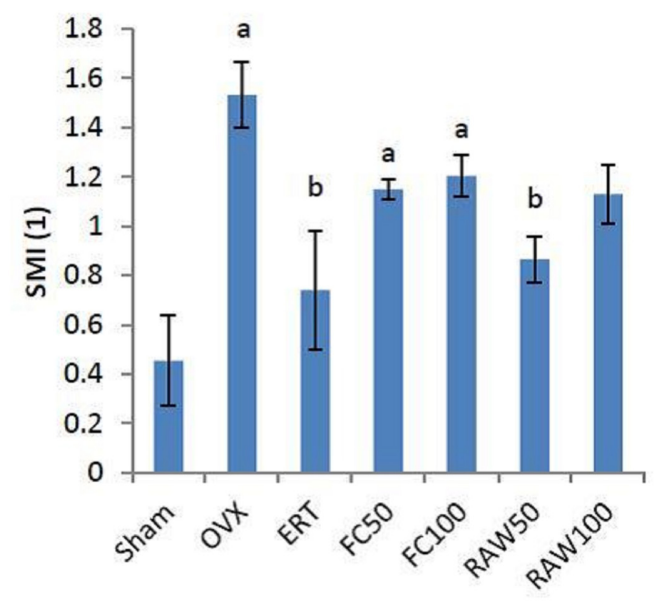

Fig. 8: Structural model index values of each group. Data presented as mean \pm SEM $(p<0.05)$ with standard error bars of the average values. ' $a$ ' indicates there was significant difference with Sham group and ' $b$ ' indicated there was significant difference with OVX group.

Connectivity density represents the maximum number of trabecular connections that can be broken where the higher the value indicates greater bone connectivity and strength (Chen et al., 2013). The structural model index is a score that reflects the rod versus plate trabecular structure, from 0 to 3 respectively (Roux et al., 2013). During aging and bone remodeling, bone structures change from plate-like to rod-like structure. The platelike structure is thicker and denser, while the rod-like structure is thinner and less dense due to the loss of bone density (Chen et al., 2013). Sham, ERT, and RAW50 showed significantly higher trabecular connectivity density (Figure 7) and significantly reduced SMI values (Figure 8) compared to OVX group. Ovariectomized rats recorded higher SMI value which indicated that osteoporotic bone had a greater amount of rod-like bone structure than platelike structure (Isaksson et al., 2011).

The degree of anisotropy (DA) is one another important biomechanical measurement to estimate fracture risk. DA describes how the structural elements are oriented within the bone volume (Francisco et al., 2011). The ideal isotropic structure is valued as 0 and a fully anisotropic structure valued as 1 . Osteoporotic bone usually recorded high anisotropy value compared to the normal bone due to loss of the bone structure. OVX group showed higher DA value which indicates that it was prone to fracture when the load is applied. However, the other groups showed no significant difference of DA value compared to OVX (Figure 9). This might be due to the small size of rat's bone where all groups were vulnerable if the load is given. 


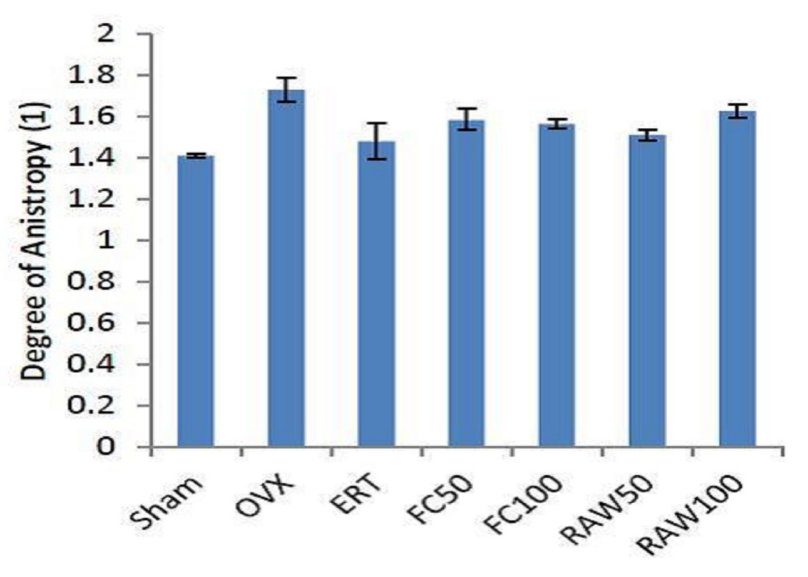

Fig. 9: Degree of anisotropy values of each group. Data presented as mean \pm SEM $(p<0.05)$ with standard error bars of the average values.

Osteoporosis associated with estrogen deficiency and highly associated with oxidative stress, a major cause of the imbalance between osteoblast and osteoclast activities. This will consequently result in a reduction of bone density. Antioxidative and anti-inflammatory properties are an important component that may play a role in protecting bone against the damaging effects of free radicals. Polyphenols, phytosterol, anthocyanin, flavonoids, isoflavones, steroids, and alkaloids are examples of antioxidant and anti-inflammatory bioactive compounds found in most plants that have been studied its effectiveness against osteoporosis. FC is one of the fruits that are rich in antioxidant and anti-inflammatory bioactive compounds that may contribute to its potential antiosteoporotic effect. In this present study, micro-CT analysis was able to provide the insight measurement of the effects of $\mathrm{FC}$ on bone quality. From the findings, FC showed promising potential as alternative supplementation against osteoporosis due to its bioactive contents, minerals, antioxidant and anti-inflammatory properties. Further studies are required to identify other aspects of $\mathrm{FC}$ as alternative treatment such as by using varieties of extractions and higher doses for better results.

\section{CONCLUSION}

Based on the micro-CT analysis, $50 \mathrm{mg} / \mathrm{kg}$ raw extract of FC was shown to have the best potential in improving osteoporotic bone changes of ovariectomized rat mode and comparable to ERT. This may due to its phytochemical content of minerals, antioxidant and anti-inflammatory properties. Thus, FC has potential as an alternative treatment for postmenopausal osteoporosis. Further studies are warranted to explore more potentials of FC against osteoporosis.

\section{FINANCIAL SUPPORT AND SPONSORSHIP}

This study was supported by the Ministry of Higher Education (MoHE) Malaysia under Faculty of Medicine and Science Health, USIM (USIM/FRGS/FPSK/32/50216).

\section{CONFLICT OF INTEREST}

The authors declare that there is no conflict of interest.

\section{ACKNOWLEDGMENT}

The authors were thankful to Encik Basri Saidi and other staffs from Department of Medical Imaging, UiTM for the facilities and assistance provided.

\section{REFERENCES}

Abrahamsen B. Bisphosphonate adverse effects, lessons from large databases. Current Opinion Rheumatol, 2010; 22:404-409.

Abujazia MA, Muhammad N, Shuid AN, Soelaiman IN. 2012. The effects of virgin coconut oil on bone oxidative status in ovariectomised rat. Evidence-based Complementary and Alternative Medicine.

Ahn BS, Yang M, Jang H, Lee HJ, Moon C, Kim JC, Jung U, Jo SK, Jang JS, Kim SH. Evaluation of the antiosteoporotic potential of Cimicifuga heracleifolia in female mice. Phytotherapy Research, 2012; 26(5):663-668.

Bernabei R, Martone AM, Ortolani E, Landi F, Marzetti E. Screening, diagnosis and treatment of osteoporosis: a brief review. Clinical Cases in Mineral and Bone Metabolism, 2014; 11(3):201-207.

Bouxsein ML, Boyd SK, Christiansen BA, Guldberg RE, Jepsen KJ, Müller R. Guidelines for assessment of bone microstructure in rodents using micro-computed tomography. Journal of Bone and Mineral Research, 2010; 25(7):1468-1486.

Çalişkan O, Aytekin Polat A. Phytochemical and antioxidant properties of selected fig (Ficus carica L.) accessions from the eastern Mediterranean region of Turkey. Scientia Horticulturae, 2011; 128(4):473-478.

Chen H, Zhou X, Fujita H, Onozuka M, Kubo KY. 2013. Agerelated changes in trabecular and cortical bone microstructure. International Journal of Endocrinology.

Chung HJ, Kyung KW, Joo PH, Cho L, Kim MR, Kim MJ, Shin JS, Ho LJ, Ha IH, Kook LS. Anti-osteoporotic activity of harpagide by regulation of bone formation in osteoblast cell culture and ovariectomy-induced bone loss mouse models. Journal of Ethnopharmacology, 2016; 179:66-75.

Das S, Crockett JC. Osteoporosis-a current view of pharmacological prevention and treatment. Drug, Design, Development and Therapy, 2013; 7:438-448.

Faienza MF, Ventura A, Marzano F, Cavallo L. 2013. Postmenopausal osteoporosis: the role of immune system cells. Clinical and Developmental Immunology.

Fonseca H, Moreira-Gonçalves D, Coriolano HJ, Duarte JA. Bone quality: the determinants of bone strength and fragility. Sports Medicine, 2014; 44(1):37-53.

Francisco JI, Yu Y, Oliver RA, Walsh WR. Relationship between age, skeletal site, and time post-ovariectomy on bone mineral and trabecular microarchitecture in rats. Journal of Orthopaedic Research, 2011; 29(2):189-196.

Goldhahn J, Little D, Mitchell P, Fazzalari NL, Reid IR, Aspenberg P, Marsh D. Evidence for anti-osteoporosis therapy in acute fracture situations-recommendations of a multidisciplinary workshop of the international society for fracture repair. Bone, 2010; 46(2):267-271.

Harzallah A, Bhouri AM, Amri Z, Soltana H, Hammami M. Phytochemical content and antioxidant activity of different fruit parts juices of three figs (Ficus carica L.) varieties grown in Tunisia. Industrial Crops and Products, 2016; 1(83):255-67.

Hernlund E, Svedbom A, Ivergard M, Compston J, et al. Osteoporosis in the European Union: Medical Management, Epidemiology and Economic Burden. A report prepared in collaboration with the International Osteoporosis Foundation (IOF) and the European Federation of Pharmaceutical Industry Associations (EFPIA). Arch Osteoporos, 2013; 8:136.

Huang WF, Tsai YW, Wen YW, Hsiao FY, Kuo KN, Tsai CR. Osteoporosis treatment and atrial fibrillation: alendronate versus raloxifene. Menopause, 2010; 17(1):57-63.

Inderjeeth CA, Chan K, Kwan K, Lai M. Time to onset of efficacy in fracture reduction with current anti-osteoporosis treatments. Journal of Bone and Mineral Metabolism, 2012; 30(5):493-503.

Isaksson $\mathrm{H}$, Töyräs J, Hakulinen M, Aula AS, Tamminen I, Julkunen P, Kröger H, Jurvelin JS. Structural parameters of normal and osteoporotic human trabecular bone are affected differently by microCT image resolution. Osteoporosis International, 2011; 22(1):167-177. 
Ito M. Recent progress in bone imaging for osteoporosis research. Journal of Bone and Mineral Metabolism, 2011; 29(2):131-140.

Jao H, Hsu J, Lee Y, Lo C, Lee HJ. Mulberry water extract regulates the osteoblast/osteoclast balance in an ovariectomic rat model. Food \& Function, 2012; 7:4753-4763.

Joseph B, Raj SJ. Pharmacognostic and phytochemical properties of Ficus carica Linn-An overview. International Journal of Pharmtech Research, 2011; 3(1):8-12.

Klein-Nulend J, van Oers RF, Bakker AD, Bacabac RG. Bone cell mechanosensitivity, estrogen deficiency, and osteoporosis. Journal of Biomechanics, 2015; 48(5):855-865.

Kim YJ, Henkin J. Micro-Computed Tomography Assessment of Human Alveolar Bone: Bone Density and Three-Dimensional MicroArchitecture. Clinical Implant Dentistry and Related Research, 2015; 1;17(2):307-13.

Kochi G, Sato S, Ebihara H, Hirano J, Arai Y, Ito K. A comparative study of microfocus CT and histomorphometry in the evaluation of bone augmentation in rat calvarium. Journal of oral science, 2010; 52(2):203211

Khosla S, Melton LJ, Riggs BL. The unitary model for estrogen deficiency and the pathogenesis of osteoporosis: is a revision needed? Journal of Bone and Mineral Research, 2011; 1;26(3):441-51.

Levis S, Lagari VS. The role of diet in osteoporosis prevention and management. Current Osteoporosis Reports, 2012; 1;10(4):296-302.

Laib A, Kumer JL, Majumdar S, Lane NE. The temporal changes of trabecular architecture in ovariectomized rats assessed by micro-CT. Osteoporosis International, 2001; 12(11):936-941.

Li F, Yang X, Yang Y, Guo C, Zhang C, Yang Z, Li P. Antiosteoporotic activity of echinacoside in ovariectomized rats. Phytomedicine, 2013; 20(6):549-557.

Liu XL, Li CL, Lu WW, Cai WX, Zheng LW. Skeletal sitespecific response to ovariectomy in a rat model: change in bone density and microarchitecture. Clinical Oral Implants Research, 2015; 26(4):392-398.

Mawa S, Husain K, Jantan I. 2013. Ficus carica L. (Moraceae): phytochemistry, traditional uses and biological activities. Evidence-Based Complementary and Alternative Medicine.

Manolagas SC. From estrogen-centric to aging and oxidative stress: a revised perspective of the pathogenesis of osteoporosis. Endocrine Reviews, 2010; 31(3):266-300.

Maquer G, Musy SN, Wandel J, Gross T, Zysset PK. Bone volume fraction and fabric anisotropy are better determinants of trabecular bone stiffness than other morphological variables. Journal of Bone and Mineral Research, 2015; 1;30(6):1000-1008.

Mcclung M, Harris ST, Miller PD, Bauer DC, Davison KS, Dian L, Hanley DA, Kendler DL, Yuen CK, Lewiecki EM. Bisphosphonate therapy for osteoporosis: benefits, risks, and drug holiday. The American Journal of Medicine, 2013; 126(1):13-20.

Miyauchi Y, Sato Y, Kobayashi T, Yoshida S, Mori T, Kanagawa H, Katsuyama E, Fujie A, Hao W, Miyamoto K, Tando T, Morioka H, Matsumoto M, Chambon P, Johnson RS, Kato S, Toyama Y, Miyamoto T. HIF $1 \alpha$ is required for osteoclast activation by estrogen deficiency in postmenopausal osteoporosis. Proceedings of The National Academy of Sciences, 2013; 110(41):16568-16573.

Mohamed N, Gwee Sian Khee S, Shuid AN, Muhammad N, Suhaimi F, Othman F, Babji AS, Soelaiman IN. The effects of Cosmos caudatus on structural bone histomorphometry in ovariectomized rats. Evidence-Based Complementary and Alternative Medicine, 2012; 2012: 817814.

Nadia ME, Khamis MF, Shuid AN. The effects of Labisia pumila extracts on bone microarchitecture of ovariectomized-induced osteoporosis rats: a micro-CT analysis. Journal of X-Ray Science and Technology, 2017; 25(1):101-112

Nadia ME, Khamis MF, Soelaiman IN, Shuid AN. The effects of Labisia pumila on postmenopausal osteoporotic rat model: Dose and timedependent micro-CT analysis. Journal of X-Ray Science and Technology, 2014; 22(2014): 503-518.
Narod SA. Hormone replacement therapy and the risk of breast cancer. Nature Reviews Clinical Oncology, 2011; 8(11):669-676.

Nishiyama KK, Campbell GM, Klinck R, Boyd SK. Reproducibility of bone micro-architecture measurements in rodents by in vivo micro-computed tomography is maximized with three-dimensional image registration. Bone, 2010; 46(1):155-161.

Parkinson IH, Fazzalari NL. Characterisation of trabecular bone structure. Studies in Mechanobiology, Tissue Engineering and Biomaterials, 2013; 5:31-51.

Peck WA. Consensus development conference: diagnosis, prophylaxis and treatment of osteoporosis. The American Journal of Medicine, 1993; 94(6):646-650.

Pereira C, López Corrales M, Martín A, Villalobos MD, Córdoba MD, Serradilla MJ. 2017. Physicochemical and nutritional characterization of brebas for fresh consumption from nine fig varieties (Ficus carica L.) grown in Extremadura (Spain), Journal of Food Quality.

Romero PA, Rivas VA. Adherence to Mediterranean diet and bone health. Nutricion Hospitalaria, 2014; 29(5):989-996.

Perilli E, Le V, Ma B, Salmon P, Reynolds K, Fazzalari NL. Detecting early bone changes using in vivo micro-CT in ovariectomized, zoledronic acid-treated, and sham-operated rats. Osteoporosis International, 2010; 21(8):1371-1382.

Ritte R, Lukanova A, Berrino F, Dossus L, Tjønneland A, Olsen A, Overvad TF, Overvad K, Clavel-Chapelon F, Fournier A, Fagherazzi G, Rohrmann S, Teucher B, Boeing H, Aleksandrova K, Trichopoulou A, Lagiou P, Trichopoulos D, Palli D, Sieri S, Panico S, Tumin, R, Vineis P, Quirós JR, Buckland G, Sánchez MJ, Amiano P, Chirlaque MD, Ardanaz E, Sund M, Lenner P, Bueno-de-Mesquita B, van Gils CH, Peeters PH, Krum-Hansen S, Gram IT, Lund E, Khaw KT, Wareham N, Allen NE, Key TJ, Romieu I, Rinaldi S, Siddiq A, Cox D, Riboli E, Kaaks R. Adiposity, hormone replacement therapy use and breast cancer risk by age and hormone receptor status: a large prospective cohort study. Breast Cancer Research, 2012; 14(3):1-14

Rizzoli R, Reginster JY, Boonen S, Breart G, Diez-Perez A, Felsenberg D, Kaufman JM, Kanis JA, Cooper C. Adverse reactions and drug-drug interactions in the management of women with postmenopausal osteoporosis. Calcification Tissue International, 2011; 89:91-104.

Roux JP, Wegrzyn J, Boutroy S, Bouxsein ML, Hans D, Chapurlat R. The predictive value of trabecular bone score (TBS) on whole lumbar vertebrae mechanics: an ex vivo study. Osteoporosis International, 2013; 24(9):2455-2460.

Svejme O, Ahlborg HG, Nilsson JÅ, Karlsson MK. Early menopause and risk of osteoporosis, fracture and mortality: a 34-year prospective observational study in 390 women. BJOG: An International Journal of Obstetrics \& Gynaecology, 2012; 1;119(7):810-6.

Sood R, Faubion SS, Kuhle CL, Thielen JM, Shuster LT. Prescribing menopausal hormone therapy: an evidence-based approach. International Journal of Women's Health, 2014; 6(1):7-57.

Spilmont M, Léotoing L, Davicco MJ, Lebecque P, Mercier S, Miot-Noirault E, Pilet P, Rios L, Wittrant Y, Coxam V. Pomegranate and its derivatives can improve bone health through decreased inflammation and oxidative stress in an animal model of postmenopausal osteoporosis. European Journal of Nutrition, 2014; 53(5):1155-1164.

Tian L, Yang R, Wei L, Liu J, Yang Y, Shao F, Ma W, Li T, Wang Y, Guo T. Prevalence of osteoporosis and related lifestyle and metabolic factors of postmenopausal women and elderly men. Medicine, 2017; 96(43).

Zheng X, Mun S, Lee SG, Vance TM., Hubert P, Koo SI, Lee SK, Chun OK. Anthocyanin-rich blackcurrant extract attenuates ovariectomyinduced bone loss in mice. Journal of Medicinal Food, 2016; 19(4):390-397.

How to cite this article:

Mohammad A, Razaly NI, Rani MDM, Aris MSM, Dom SMd, Effendy NM. A Micro-computed Tomography (microCT) Analysis of Postmenopausal Osteoporotic Rat Models Supplemented with Ficus carica. J App Pharm Sci, 2018; 8(06): 039-045. 